\title{
Long term year results of fresh femoral neck fractures treated by cancellous screw and fibular autograft
}

\begin{abstract}
Femoral neck fractures in adults have a poor prognosis because of high incidence of nonunion and aseptic necrosis. Prosthetic replacement of the femoral head is reserved for the physiologically older patients while osteosynthesis with preservation of femoral head is the treatment of choice for fracture neck femur in younger adults. Various types of bone graft supplementation have been advocated to reduce the incidence of nonunion and avascular necrosis. We tried cancellous screw fixation supplemented by fibular autologous grafting to overcome nonunion and avascular necrosis. Thirty-five (M-18: F-17) skeletally mature patients (mean age 49.38 years) of fresh femoral neck fracture were treated. Weight bearing was allowed only after 3 months, or later if the radiological signs of union was not seen. All fractures showed union at one year follow up. Complications included, avascular necrosis ( 2 cases), broken fibular graft ( 3 cases), screw back out with collapse ( 2 cases), penetration of the femoral head articular surface by screw and graft (1 case each). Patients are able to sit cross-legged and squatting position. Cancellous screw fixation and fibular autologous grafting is a safe, cost effective and reliable surgical technique for treating femoral neck fractures in properly selected patients.
\end{abstract}

Keywords: Fractures, Femur neck, Fibular Autograft, Cancellous screw
Volume I Issue 3 - 2014

\author{
Sudhir Singh, Dharmendra Kumar, Sanjiv \\ Kumar \\ Department of Orthopaedics, Era's Lucknow Medical College, \\ India
}

Correspondence: Sudhir Singh, Head Department of Orthopaedics, Era's Lucknow Medical College, Lucknow, India, Email susi59@live.in

Received: November 16, 2014 | Published: November 27, 2014

\section{Introduction}

Femoral neck fractures in adults have a poor prognosis due to high incidence of non-union and aseptic necrosis. The incidence of avascular necrosis of head of femur is reported to remain as high as $15-33 \%$ and that of nonunion is $10-30 \%{ }^{1,2}$ Prosthetic replacement of the femoral head is reserved for the physiologically older patients in whom internal fixation is unlikely to succeed. Osteosynthesis with preservation of femoral head is the treatment of choice for fracture neck femur in elderly and younger adults. ${ }^{3,4}$ Implants of various designs (Smith Peterson's nail, angled blade plate, Dynamic hip screw, single or multiple cancellous screws) with or without Valgus osteotomy has been used to fix these fractures. Various types of bone graft supplementation i.e.

A) Muscle pedicle based

i) Quadratus femoris

ii) Sartorius

iii) Gluteus medius oriv iliac crest graft.

B) Free fibular

i) Single graft

ii) Dual graft.

C) vascularized fibular graft have been advocated along with or without internal fixation along with valgus osteotomy to treat neglected fractures and ununited femoral neck fractures to promote union..$^{5-17}$ Bone graft supplementation by using free fibular grafting was in past used in fifth decade but with less satisfying results. ${ }^{18-20}$ In India it was revived in 1981 and first results were published in 1986. ${ }^{13}$ Bone graft supplementations by fibula in fresh fractures have been reported in only two studies. ${ }^{13,15}$ We evaluated the use of nonvascularized fibular strut graft with cancellous screw fixation for treatment of fresh femoral neck fractures. Bone graft supplementation by using free fibular grafting was in past used in fifth decade but with less satisfying results. ${ }^{18-20}$ In India it was revived in 1981 and first results were published in $1986 .{ }^{13}$ Bone graft supplementations by fibula in fresh fractures have been reported in only two studies. ${ }^{13,15}$ We evaluated the use of non-vascularized fibular strut graft with cancellous screw fixation for treatment of fresh femoral neck fractures.

\section{Materials and methods}

The study was cleared by the research cell and ethical committee of the institute. Informed and written consent was taken from all patients included in the study. From January 2000 to December 2002, forty-five patients presented to us with fresh $(<3$ weeks) femoral neck fractures. Ten patients did not give consent and were not included in the study. Thirty five (M:18: F:17) skeletally mature patients, with mean age 49.38 years (range $40-65$ years), having less than 3 weeks old femoral neck fractures were treated by closed reduction and fixation by one or two $6.5 \mathrm{~mm}$ cannulated cancellous screw and fibular autograft. Three (10\%) patients had garden type II fractures, 18 had type III and rest 14 had type IV fractures.

The fractures were close reduced under general anesthesia (Lead better or Whitman technique) with image intensifier. Post reduction a Garden alignment index of 1600-1800 in anteroposterior view and 00200 in lateral views were taken as acceptable position. Reduction was graded as satisfactory in $75 \%$ i.e. anatomical or slight valgus and less than satisfactory in $25 \%$. Trochanter and upper femur was exposed subperiosteally by a mid-lateral incision and fixation achieved by one or two $6.5 \mathrm{~mm}$ cannulated cancellous screws in 17 and 18 cases respectively. The bed for the graft was prepared by DHS triple reamer. The fibular graft of appropriate length was harvested from the ipsilateral leg and as per the technique described in the literature. ${ }^{13}$ The prepared fibular diaphyseal graft was gently tapped in the graftbed. The wound was closed in layers. Post-operative mobilization in 
bed, isometric quadriceps exercises and knee bending was encouraged from the second post-operative day. Non-weight bearing crutch walking was allowed at 6 weeks. Weight bearing was permitted only after union, which took about 3 months. The patients were followed up at regular interval of three months till one year and then at six monthly intervals for next 2 years. Finally after further 5 years i.e. a total of 8 year follows up. Clinical assessment included pain, hip joint movement, limb length discrepancy and stability of hip. Treatment outcome was assessed using Harris hip score, for which the maximum score is 100 , which included pain (44points), function ( 47 points) and deformity (4 points).

\section{Results}

Thirty-one patients completed a follow-up of 3years (mean 32.7 months). At 8 year follow up only 24 patients responded, 6 patients had migrated to another location with no forwarding address and one patient died with causes unrelated to fracture.

\section{Union}

All patients showed union by year end. Thirty of 35 patients $(85.7 \%)$ showed union by the end of 6 months, 4 fractures united by 9 months and one fracture united by year end.

\section{Avascular necrosis}

Only two cases showed asymptomatic avascular necrosis (AVN) of head. The first case was 40 years old and he developed signs of AVN after two and half year of fixation, but he was asymptomatic. The second patient, 50 years old, showed changes of AVN on radiographs after one and half year after surgery. This patient does have pain but refused a second surgery. He needs oral analgesics 4-5 days in a month. Both are community ambulators and are back to their previous level of social function.

\section{Penetration of femoral head}

Penetration of the articular cartilage by screw (long screw) and by fibular graft (long graft) was observed in post-operative radiographs in one case each. The screw was withdrawn by $5 \mathrm{~mm}$ in a second surgery done under local anesthesia.

\section{Pain in hip joint}

Ten patients have pain on long distance walking and 6 patients have slight limp while walking.

\section{Functional results}

Functional range of movements was achieved in all cases. All patients are able to sit cross-legged and squat (Figure $1 \& 2$ ).

Other complications were- broken fibular graft, coxa vara and leg length discrepancy. Fibular graft was broken and loss of reduction was seen in 3 cases, two of which had the fracture fixed by only one screw and in these cases there was a second trauma. One of them $(60$ year male) had to jump from a cycle rickshaw in order to avoid being hit by another vehicle. The second ( 28 year female) had been hit by a pedal-cyclist. The third (60 year female) started bearing full weight after 6 weeks only. Bipolar arthroplasty was done in two cases and Mcmurray's osteotomy was done in one case. Screw back out with settling of the fracture was seen in 2 cases. Shortening of less than $2 \mathrm{~cm}$ was seen in 4 cases. No superficial or deep infections were seen.

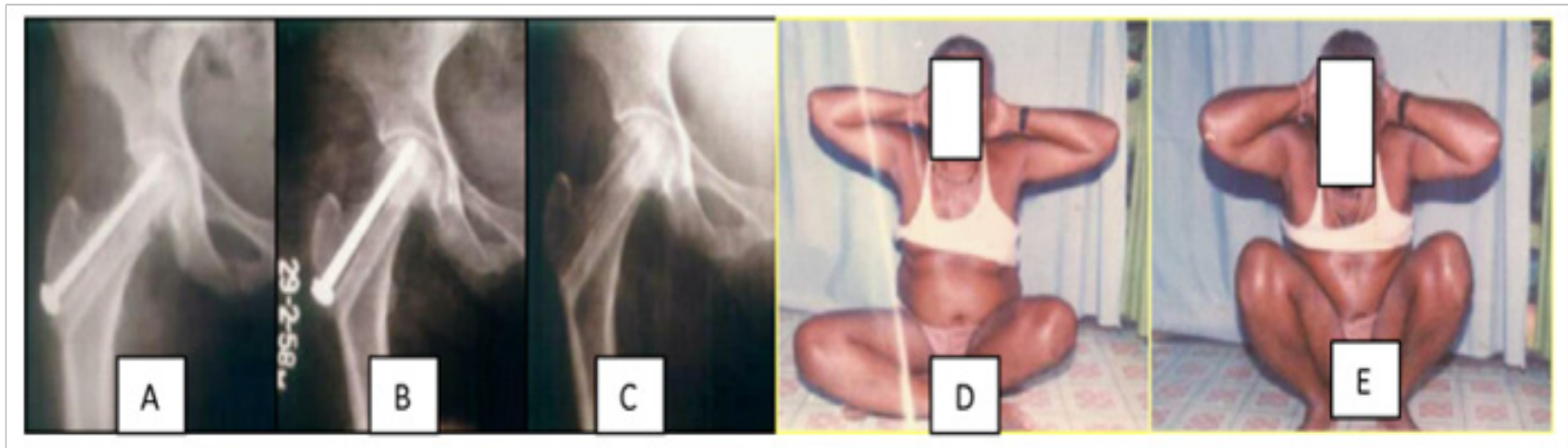

Figure I

A: Immediate Post-operative $x$-ray showing fracture fixed in slight valgus.

B: 3 years follow-up: Fracture has united.

C: No evidence of $A V N$ seen8 years later.

D: Patient squatting.

E: Cross - legged sitting.

\section{Discussion}

Femoral neck fractures occur commonly in elderly patients and usually due to minor trauma. But when this fracture occurs in relatively younger patients the amount of trauma is usually much more. In the treatment algorithm of femoral neck fracture, the patients

who are less than sixty-five years old and do not have any chronic medical illnesses should be managed with immediate reduction and internal fixation of the fracture with $6.5 \mathrm{~mm}$ cancellous screws with the aim of preserving patients own natural hip. ${ }^{3,21,22}$ The incidence of nonunion and avascular necrosis is much higher in younger patients, probably because of much more soft tissue injury and vascular insult 
occurring due to greater amount of trauma. ${ }^{23,24}$ Cancellous screws have been preferred over DHS implant assembly for internal fixation in younger patients with good bone stock, while DHS or angled blade-plate with additional screw has been preferred in patients with osteoporotic bone. ${ }^{25-28}$

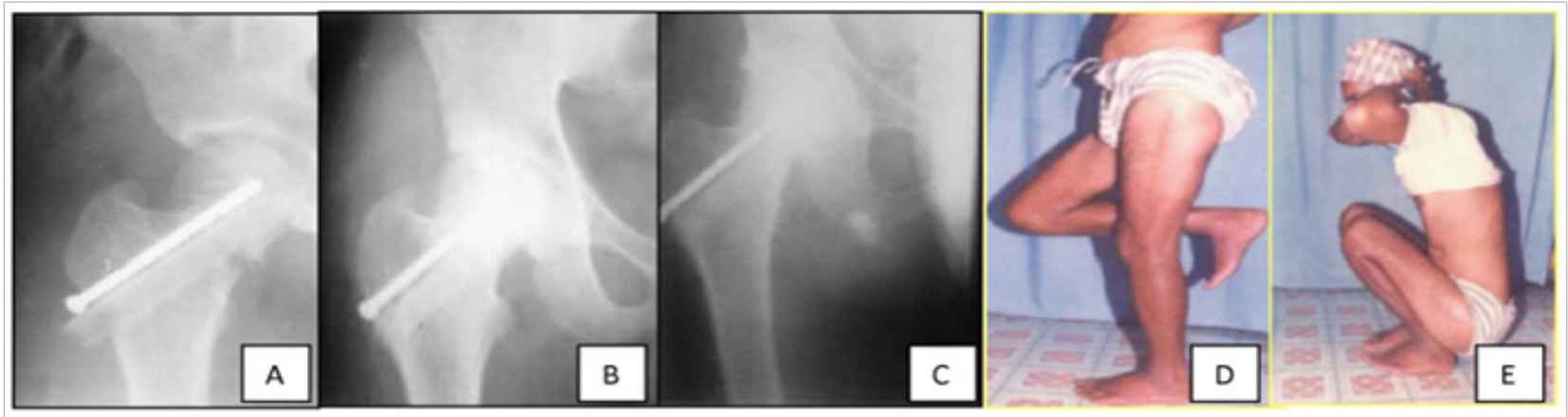

Figure 2

A: Immediate post-operative $x$-ray.

B: 7 months later fracture has united.

$\mathrm{C}$ : No evidence of AVN seen 8 years later.

$\mathrm{D} \& \mathrm{E}$ : Showing patient standing and squatting.

\section{Why a graft?}

Bone grafts procedure has been supplemented along with internal fixation in cases where the treatment was delayed due to some reason or the patients had ununited fractures at the time of presentation for treatment. $^{7-9,13,23,29}$ Primary autologous fibular grafting along with cancellous screw fixation in fresh cases has been done and good results have been reported by two workers. ${ }^{13,15}$ In this study we have used fibular autograft in all our patients. Since being young, they do not have the option of replacement of femoral head. Hence, we believe that maximum and best have to be done at the first opportunity to save the patient's own biological femoral head by augmenting with bone graft.

\section{Choice of graft}

Various types of bone grafting procedures ranging from phemister graft, nonvasculrised (iliac crest graft, fibular graft), vascularized muscle pedicle (Quadratus femoris, Sartorius, Gluteus medius) based grafts have been used in the treatment of femoral neck fractures but no single technique have shown superiority of one technique over other techniques in a randomized controlled trial. We chose autologous ipsilateral fibular graft as the procedure can be easily done at simpler setups across the developing world. Moreover, it being cortical and tubular would not only provide mechanical strength like a screw in maintaining the reduction but also provide osteogenic stimulus across the fracture site. Multiple drill holes in the grafts also encourage the in growth of the creeping substitution. Hence, fibular graft acts as a "biodegradable graft-implant". Dual fibular grafting with or without cancellous screw has been done for neglected fracture neck of femur in adult patients and excellent to fair results have been reported by many. ${ }^{12,20}$ The authors believed that use of double fibular strut graft acts as double Smith Peterson nail because of the trephine shape of fibula. This provides enough mechanical stability till fracture union. Muscle pedicle bone grafting and vascularized fibular grafting are probably superior technique but are skill dependent, time consuming, expensive and require microsurgical sophisticated equipments which are not readily available at most of the tertiary level hospitals in India.

\section{Fate of fibular graft}

The fate of the graft has not been studied and reported as yet, but it is believed that it gets incorporated with the host bone rather than getting resolved. The fibular graft starts fusing with the host bone and is seen as gradual decrease in the density of the graft and loss of cortical details of the graft. Over a sufficiently long period, the fibula is replaced by trabecular pattern of cancellous bone. In this series there were two cases where fibular graft was broken and subsequent replacement arthroplasty was done. In these cases, on gross examination of the cut section of removed femoral head did show that the fibula was getting fused with the host bone. The exact time frame of the graft incorporation has not been studied by any worker. We believe that autologous fibular graft strut graft should be used as an adjuvant to anatomic reduction and internal fixation in all fresh femoral neck fractures primarily, especially in younger adults, as this provides a more osteogenic environment for fracture healing without jeopardizing the already precarious blood supply to the femoral head. Randomized controlled trials comparing all alternatives with sufficiently long follow ups will be able to provide ultimate answers to this vexed question choice of grafting in fresh femoral neck fractures, but this case series does prove its durability, safety and affectivity in simple settings.

\section{Conclusion}

We conclude that fresh femoral neck fractures can be safely treated by closed/open reduction cancellous screw fixation supplemented primarily by fibular graft. The results are quite encouraging if the anatomical or slight valgus reduction is achieved and strict adherence to the post-operative rehabilitation schedule is followed.

\section{References}

1. Wu CC, Shih $\mathrm{CH}$, Chen WJ, et al. Treatment of femoral neck nonunion with a sliding compression screw: Comparison with and without subtrochanteric valgus osteotomy. J Trauma. 1999;46(2):312-317.

2. Huang $\mathrm{CH}$. Treatment of neglected femoral neck fractures in young adults. Clin Orthop Relat Res. 1986;(206):117-126. 
3. Swiontkwoski MF. Intracapsular fractures of hip-current concept review. J Bone and Joint Sur. 1994;76-A;129-138.

4. Sandhu HS. Management of fracture neck of femur. Indian J Orthop. 2005;39(2):130-136.

5. Bakshi DP. Treatment of post-traumatic avascular necrosis of the femoral head by multiple drilling and muscle pedicle bone grafting and internal fixation. J Bone and Joint Surg. 1983;65-B(2):68-73.

6. Bonfiglio M, Bardenstein MB. Treatment by bone grafting of aseptic necrosis of the femoral head and nonunion of the femoral neck (phemister technique). J Bone Joint Sur Am. 1958;40(6):1329-1346.

7. Hou SM, Hang YS, Liu TK. Ununited femoral neck fractures treated by open reduction and vascularized iliac bone graft. Clin Orthop Relat Res. 1993;(294):176-180

8. Huang $\mathrm{CH}$. Treatment of neglected femoral neck fractures in young adults. Clin Orthop Relat Res. 1986;(206):117-126.

9. Leung PC, Shen WY. Fractures of femoral neck in young adults. A new method of treatment for delayed and nonunions. Clin Orthop Relat Res. 1993;(295):156-160

10. Meyers MH, Harvey JP, Moore TM. Treatment of displaced subcapital and transcervical fractures of femoral neck by muscle pedicle bone graft and internal fixation. J Bone Joint Surg Am. 1973;55(2):257-274.

11. Azam MQ, Iraqi A, Sherwani M, et al. Free fibular strut graft in neglected femoral neck fractures in adult. Indian J Orthop. 2009;43(1):62-66.

12. Yadav SS. Dual fibular grafting. A new technique of fixation of the femoral neck fractures. Indian J Orthop. 2005;39(1):21-25.

13. Nagi ON, Gautam VK, Marya SK. Treatment of femoral neck fractures with a cancellous screw and fibular graft. $J$ Bone Joint Surg Br 1986;68(3):387-391

14. Kainth GS, Yuvarajan P, Maini L, et al. Neglected femoral neck fractures in adults. J Orthop Surg (Hong Kong). 2011;19(1):13-17.

15. Zahid M, Bin Sabir A, Asif N, et al. Fixation using cannulated screws and fibular strut grafts for fresh femoral neck fractures with posterior comminution. J Orthop Surg (Hong Kong). 2012;20(2):191-195.

16. Sen RK, Tripathy SK, Goyal T, et al. Osteosynthesis of femoral-neck nonunion with angle blade plate and autogenous fibular graft. Int Orthop. 2012;36(4):827-832.
17. Pal CP, Kumar B, Dinkar KS, et al. Fixation with cancellous screws and fibular strut grafts for neglected femoral neck fractures. J Orthop Surg (Hong Kong). 2014;22(2):181-185.

18. Inclan A. Late complications in fracture neck of the femur treated by nailing, bone grafting or both. J Int Coll Surg. 1946;9:36-50.

19. Patrick J. Intracapsular fractures of femur treated with a combined SmithPeterson nail and fibular graft. J Bone Joint Surg Am. 1949; 31(1):67-80.

20. Jaiswal A, Pruthi KK, Goyal RK. Evaluation of osteosynthesis with dual fibular bone grafting for neglected femoral neck fracture. J Clin Orthop Trauma. 2013;4(2):58-69.

21. Bray TJ. Femoral neck fracture fixation. Clinical decision-making. Ciln Orthop Relat Res. 1997;(339):20-31.

22. Cuckler JM, Tamarapalli JR. An algorithm for management of femoral neck fractures. Orthopedics. 1994;17(9):789-792.

23. Nagi ON, Dhillon MS, Agarwal AK. Formalin preserved fibular allograft in neglected femoral neck fractures. Indian journal of orthopaedics. 1999;33:33-35.

24. Protzman RD, Burkwalter WF. Femoral-neck fractures in young adults. J Bone Joint Surg Am. 1976;58(5):689-695

25. Fehr HR, Steiner W, Noesberger B. Osteosynthesis in dislocated femora neck fractures (Garden 3 and 4). Long-term results and treatment concept. Helv Chir Acta. 1993;59(4):539-542.

26. Parker MJ, Blundell C. Choice of implant for internal fixation of femoral neck fractures. Meta-analysis of 25 randomized trials including 4, 925 patients. Acta Orthop Scand. 1998;69(2):138-143.

27. Peter RE, Fritschy D. Fracture of femoral neck: therapeutic approach Helv Chir Acta. 1993;59(5-6):971-984.

28. Renz N, Bilat C, Bereiter H, et al. The dynamic hip screw (DHS) in femoral neck fractures. Helv Chir Acta. 1993;59(4):543-546.

29. Nagi ON, Dhillon MS, Goni VG. Open reduction, internal fixation and fibular autografting for neglected fracture of the femoral neck. $J$ Bone Joint Surg Br. 1998;80(5):798-804. 